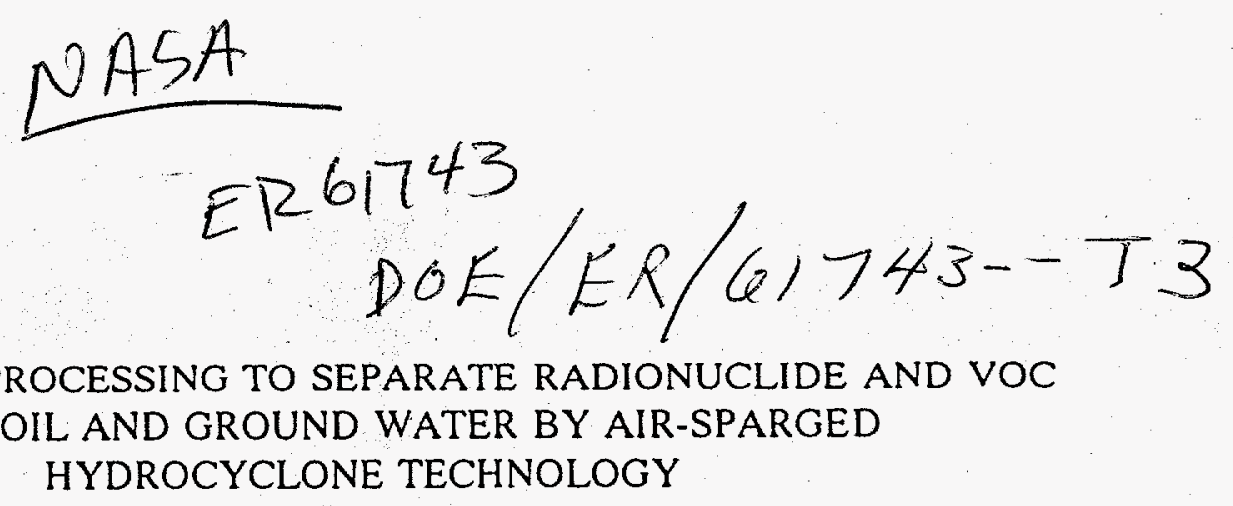

Final Report

Submitted To:

Joseph B. Paladino EM - 521

19901 Germantown Road

Germantown, MD 20874

Submitted By: Ye Yi

Principal Investigator

Advanced Processing Technologies, Inc.

P.O. Box 58131

Salt Lake City, UT 84158 - 0131

March 29, 1996

\title{
DISCLAIMER
}

This report was prepared as an account of work sponsored by an agency of the United States Government. Neither the United States Government nor any agency thereof, nor any of their employees, makes any warranty, express or implied, or assumes any legal liability or responsibility for the accuracy, completeness, or usefulness of any information, apparatus, product, or process disclosed, or represents that its use would not infringe privately owned rights. Reference herein to any specific commercial product, process, or service by trade name, trademark, manufacturer, or otherwise does not necessarily constitute or imply its endorsement, recommendation, or favoring by the United States Government or any agency thereof. The views and opinions of authors expressed herein do not necessarily state or reflect those of the United States Government or any agency thereof. 


\section{Review of Project Background}

There are a wide variety of radioactive, toxic, and heavy metal contaminants in the ground waters and soils at DOE facilities. Some of the most common are uranium, technetium, trichloroethylene, and polychlorinate bipheryls.

The project is a challenging task based on several key factors. For the removal of radionuclide or heavy metal particles, first, on a mass fraction basis there is only a small amount of radionuclide particles in either water or soil. In this way, a successful separation process must be capable of removing small amount of radionuclide particles or other heavy metals from a very large quantities of soil or water. This feature poses a significant difficulty $\cdots$ most separation technologies which have a low specific processing capacity. Second, in addition to the need to have a high specific processing capacity, the separation technology must be able to selectively separate fine particles. For example, it is expected that most of radionuclide particles as well as $10-30 \%$ of the soil particles (depending on the site) are in the size range of less than 100 microns. Thus, a successful separation process must also be capable of efficiently removing minute quantities of small-sized particles from large quantities of soil of the same fine particle size. These two key factors are of critical importance and pose tremendous difficulties for any conventional technology available today.

In addition to above two factors for radionuclides, another problem associated with these sites is that there are also volatiles and oils involved either in soil or water. For example, trichloroethylene is a toxic VOC substance highly regulated by EPA. Pollution by volatile organic compounds (VOC) and associated processing technologies are three types: a) solids; b) air; and c) water. For VOC-laden solids, common technology used to destruct VOC is thermal 
oxidation (thermal incineration). For VOC-laden air, technologies used to destruct VOC include thermal oxidation, catalytic oxidation, adsorption, flaring, condensation, biofiltration, membrane filtration, and UV oxidation. For VOC-laden water, technology used is aeration stripping. After VOC is stripped-out from water into the air, cleaned water is discharged and VOC-laden air generated by the process then can be either processed by air destruction technologies, or discharged into the atmosphere (depending on sites, amount and permit). The removal of volatile organic compounds from water has been practiced for many years. Direct sparging through water columns (bubble column aeration), packed towers, and a wide variety of specific designs combining differ ${ }^{-+}$aeration techniques have been used. Nevertheless, the problem is that many conventional aeration machines do not operate properly at high air flow rates. Further, packed column strippers occupy a large floor space due to its low specific processing capacity (i.e., processing capacity per unit volume of the reactor). For example, a typical conventional stripper has a diameter as large as $10 \mathrm{feet}$, and its height ranges from 15 to 25 feet, resulting in a significant investment in equipment and building floor space.

In addition to above cited challenges to remove each individual contaminant by an individual technology, however, the most important issue herein is that, many DOE sites are contaminated by multi-contaminants, not a single compound at each site. To decontaminate a site containing multi-contaminants, a combination of different types of technologies/equipment is needed. This practice significantly raises the cost in decontamination process and causes a complexity and difficulty of the process as compared with single technology for a single application which, as stated above, is already difficult.

Take VOC as an example, if both ground soil and ground water are contaminated by VOC 
at a site, separate technologies to remove VOC from soil (such as thermal incineration) and water (such as stripping), respectively, are needed. However, during the process, VOC in soil will migrate into discharged cleaned water and vise versa. This situation becomes more complicated if the site also contains other contaminants such as radionuclide, oil, DNAPL, etc..

In view of above situations, Advanced Processing Technologies, Inc. (APT) has proposed a differential separation concept, i.e., using one key technology to process/remove different contaminants step-by-step through proper engineering and circuit design. The successful development of such a technology/circuit will significantly reduce the complexity, capital equipment cost, and operation cost during decontamination process.

The air-sparged hydrocyclone technology (will be referred as ASH later) is one of the technology in environmental fields has been under the development by APT during the past several years and the technology has been preliminarily demonstrated to have a diversified functions to remove different contaminants from different streams. This may provide a unique opportunity and offer a strong potential for the removal of radionuclides, VOC, oil, DNAPL and others from contaminated soil and groundwater through a differential removal process.

\section{Phase I Technical Objective and Technical Tasks}

The Phase I program basically contains one key technical objective which is reiterated herein "The Phase I technical objective is to investigate the feasibility of removal of both radionuclide and VOC with air-sparged hydrocyclone technology through a differential processing strategy. The program will be emphasized on high removal efficiency, high processing capacity, and low processing cost as compared with any other technologies available today. In addition, 
of equal importance is the intent to establish scale-up criteria for the technology for this particular application".

The proposal was funded in September 1995. Due to SBIR regulation, the project time was reduced to six months by DOE Contracting Office. In October, a project kick-off meeting was held at Washington D.C. by APT, DOE Technical Program Manager and other related DÖE program coordinates. During this project review meeting, the following project scopes were added/slightly modified:

a) If technically possible, APT shall include oil and DNAPL in streams to be processed in viev the complexity of site contamination situations;

b) In view of complexity of site management and contractual structures of DOE facilities, paper work needed to accomplish (administrative, environmental, safety, and others), and a short time available for Phase I program, if possible, APT shall conduct a preliminary on-site test. If not, APT shall accomplish its Phase I objective as much as possible through other testing and engineering work.

\section{Results and Accomplishment of Phase I Program}

During past four months, APT has conducted significant amount of work/study through testing/engineering/analysis at its facility. The concept and feasibility of ASH technology for proposed applications has been clearly demonstrated. Also, as anticipated, at the time of this report writing, APT has not been able to finish the work needed for a preliminary on-site test. Details are provided herein.

Following works related to this project have been accomplished. 
A) Radionuclide particle removal -- APT in the past has conducted a preliminary test to remove plutonium oxide particles from soil at Nevada-Test-Site with the air-sparged hydrocyclone technology. At the time of Phase I proposal writing, both data and analysis were yet not completed. Now the data are available and a typical result/analysis from a record run (true chemical lab analysis) is given in Figure 1. For those tests which were not categorized as a record run (run-and-see, through Am 241 anal; sis/estimates), an even better separation was observed.

By carefully studying tests data from both record run and non-record run, APT feel that an ASH unit can relati ely easily achieve a concentration factor of 3 or more for this field of application. That means, during the process, most of radionuclide particles plus part of noncontaminant such as clean soil particles will be split into the concentrate stream, and the concentration of radionuclide particles in the concentrated stream is three times of the concentration in the stage feed. Based on this consideration, a multi-units ASH system has been preliminarily engineered at APT during the Phase I program. A schematic drawing as well as mass balance for the system is provided in Figure 2.

As shown in the figure, by maintaining a concentration factor of 3 for each stage unit (for example, $45 / 15=3,60 / 20=3,75 / 25=3$, etc), an efficient separation thus can be obtained through a circuit with a cluster of four ASH units. For example, for the system given in Figure 2, if $25 \%$ soil particles and $75 \%$ radionuclide particles are concentrated into a stage concentrate stream during each stage feeding, then from point $\mathrm{A}$ to $\mathrm{F}$, the cleaned stream will contain $88 \%$ soil particles and only $19 \%$ radionuclide particles. Further, since most of radionuclide particles are fine in size as explained in Phase I proposal and most coarse soil particles are free of the 


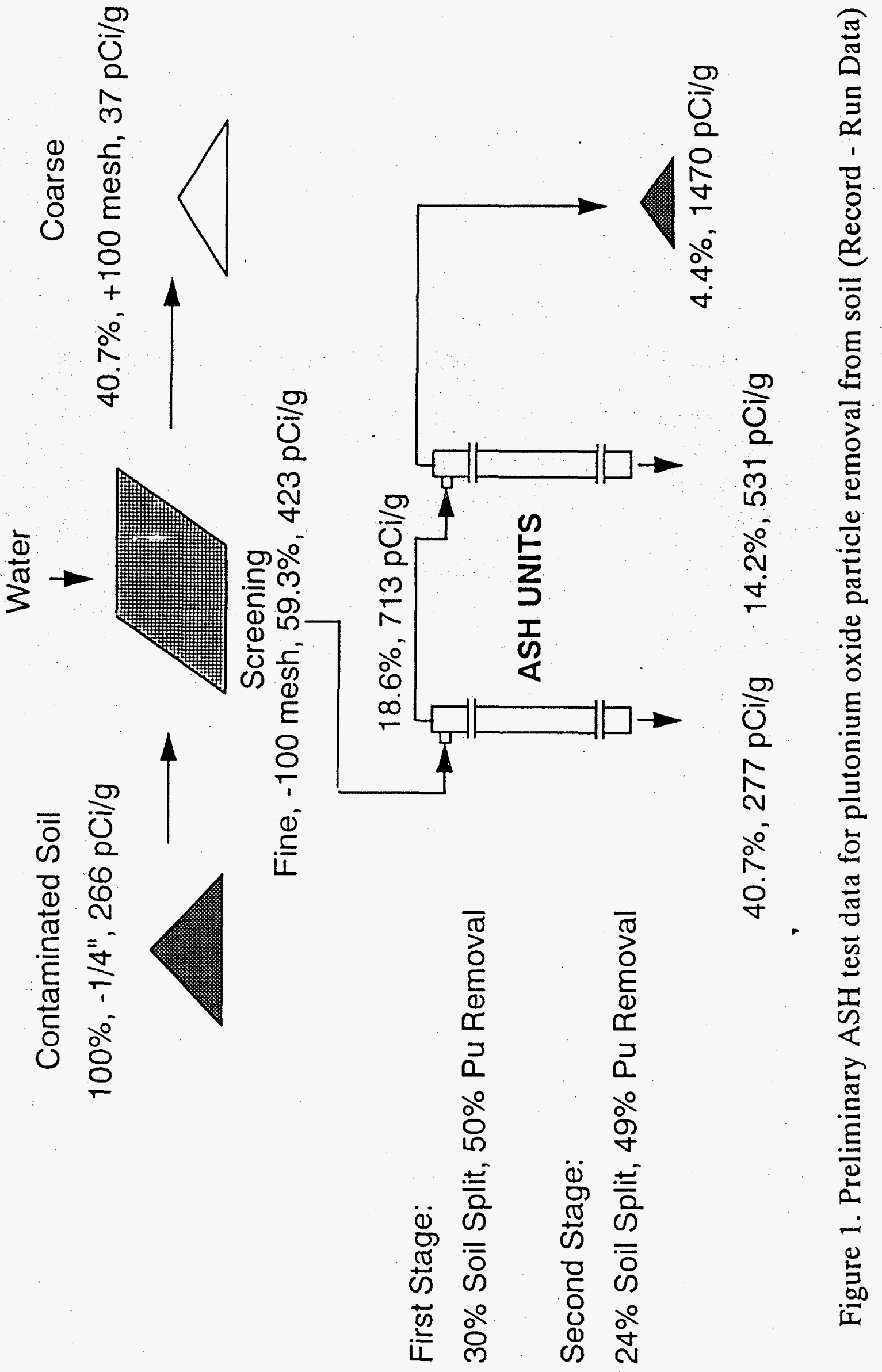




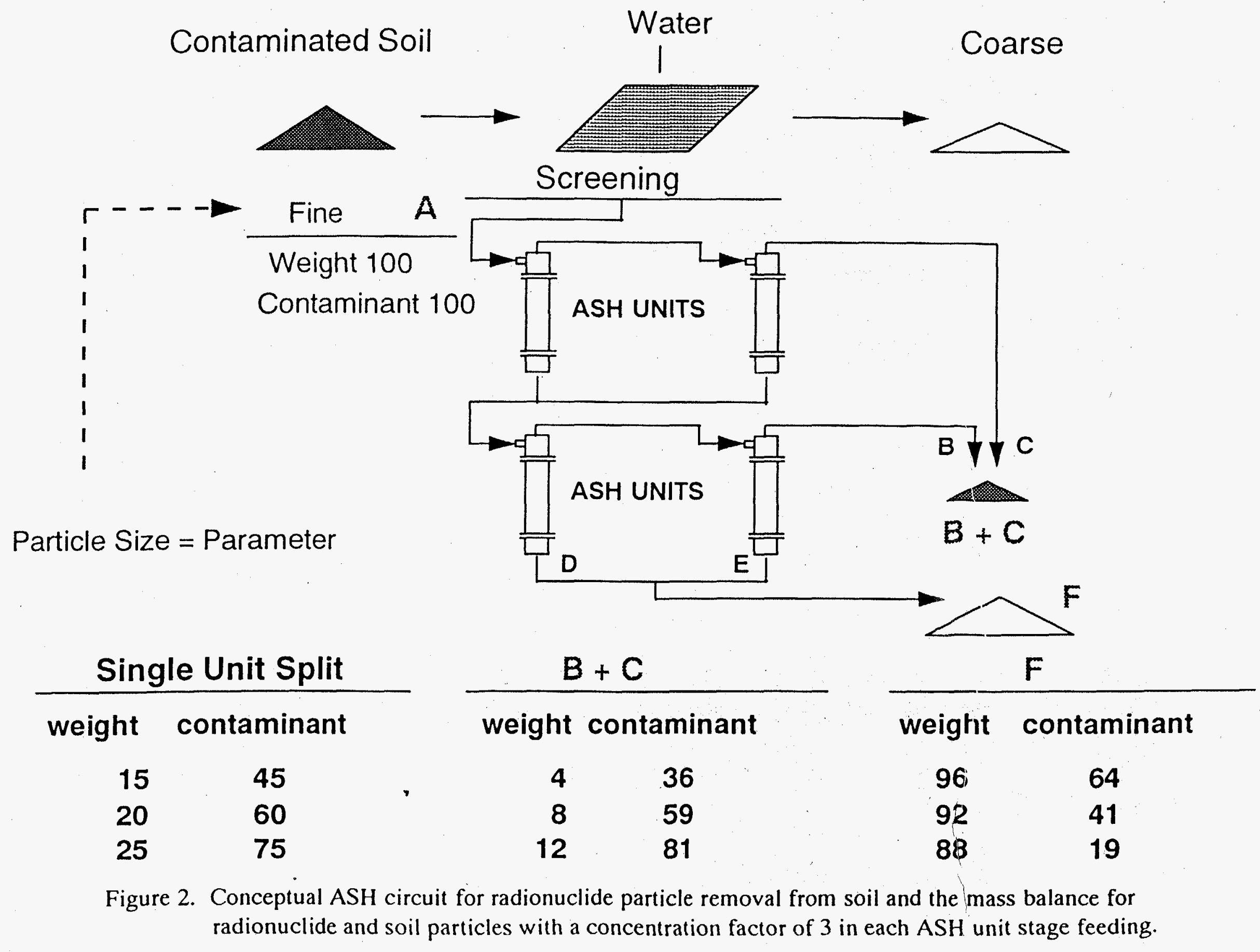


contaminants (please refer to Figure 1 for reference), combination of the stream $F$ with oversize material from screening will probably provide a soil recovery of more than $95 \%$ with more than 95\% radionuclide particles removed.

Work conducted during Phase I program also included preliminary estimate on capital equipment cost and operation cost for the system showing in Figure 2. Data are provided in Table 1. As can be seen in Table 1, for a self-contained mobile system with a processing capacity of about $50 \mathrm{tph}$ contaminated soil, the capital equipment cost is estimated at about $\$ 550,000$ while the operation cost is estimated at about $\$ 5.4 / \mathrm{t}$ soil. Man power cost for operators (2) is included into this $\$ 5.4 / \mathrm{t}$ number. In this way, the system can be utilized to efficiently concentrate radionuclide particles from contaminated soils into a highly concentrated stream and then disposed of at a reduced volume and disposal cost.

B) VOC stripping from water -- A significant amount of work both in ASH-2C testing and calculation/engineering based on actual data has been conducted. Selected results are summarized in Table 2, given as power cost versus removal efficiency. In the table, the work for TCE removal was supported by Radian Corporation. As can be seen in Table 2, as an example, for TCE removal, at a removal efficiency of $97 \%$, the power cost for ASH system to strip the TCE out is $\$ 0.10$ per every 1,000 gallons of water processed.

It needs to be pointed out here that, for ASH system, the power cost listed in Table 2 is based on removal efficiency (\% removed) given in the table, not the concentration in feed and discharge limit. For streams with different feed concentrations and discharge requirements, actual power cost is the power cost number listed in Table 2 multiplied by a factor, $\mathrm{n}$, which is 
Table 1. Estimated Capital Equipment Cost (50 tph system) and Operation Cost of ASH System for Radionuclide Removal from Soil

System: $\quad$ Self-Contained Mobile System with Twelve 6" ASH, Tanks, Agitators, Motors, Compressor, Flow Regulators, Control Systems, etc.

Capacity: $\quad 50$ tph, $\sim 375,000$ tpy

Processing Criteria: $>80 \%$ Radionuclide Removal, $<20 \%$ Soil Split

Space Requirement: Mounted on a 8' x 40' Trailer Cost: $\quad \sim \$ 550,000$, Including Trailer

Power Cost:

Reagent Cost:

Labor Cost:

Maintenance Cost:

Total: $\sim 300 \mathrm{hp}, \$ 0.2 / \mathrm{t}$ soil

$\sim \$ 4 / \mathrm{t}$ so ${ }^{\circ} 1$

$\sim \$ 0.8 / \mathrm{t}$ soil (two operators)

$\sim \$ 0.4 / \mathrm{t}$ soil

$\$ 5.4 / \mathrm{t}$ soil 
Table 2. List of Power Cost Versus the VOC Stripping Efficiency for Several Tested VOC Compounds with ASH-2C System.

Contaminant

$$
\text { Concentration Concentration In }
$$

Removal

In Tested Water. Discharged Water

Efficiency

Power Costs

Benzene

$100 \mathrm{ppm}$

$0.25 \mathrm{ppm}$

$99.8 \%$

0.04-0.08

Toluene

$30 \mathrm{ppm}$

$0.08 \mathrm{ppm}$

$99.7 \%$

0.03-0.06

Total Xylene

$22 \mathrm{ppm}$

$<0.1 \mathrm{ppm}$

$>99.5 \%$

0.03-0.06

Octene

DCE

$550 \mathrm{ppm}$

$<10 \mathrm{ppm}$

$>98.2 \%$

$0.01-0.02$

$7200 \mathrm{ppm}$

$750 \mathrm{ppm}$

$89.6 \%$

$0.05-0.10$

DCE

$200 \mathrm{ppm}$

$<1 \mathrm{ppm}$

$>99.5 \%$

Heated Water

TCE

Underground

$100 \mathrm{ppb}$

$<3 \mathrm{ppb}$

$>97.0 \%$

Water

Winter Operation

calculated as:

$\mathrm{n}=\log$ (discharge limit/feed concentration)/log(1-removal efficiency)

For example, for benzene stripping from water, if feed contains $1,000 \mathrm{ppm}$ benzene and discharge limit is $0.00625 \mathrm{ppm}$, the $\mathrm{n}=2$, the actual power cost is $\$ 0.80$ per every 1,000 gallons of water processed. The same way, if feed contains $10 \mathrm{ppm}$ and discharge limit is $1 \mathrm{ppm}$, the power cost is $\$ 0.14$ per every 1,000 gallons of the water processed.

As a comparison, Table 3 provides a general cost number for other three technologies based on a $95 \%$ stripping efficiency for several selected VOC compounds. Further, if we assume that the water to be processed contains no any soil particles (ideal case, so that packing media of a packed tower will not be plugged by solid particles and associated operating cost in 
Table 3. Approximate Range of Costs for Different Processes to Remove VOC from Water (cents/1,000 gal.)

Compound Diffused Air Packed Tower GAC Adsorption

\begin{tabular}{lllr}
\hline & & & \\
Trichloroethene & $40-60$ & $20-40$ & $25-55$ \\
Tetractloroethene & $45-60$ & $20-40$ & $20-30$ \\
1,1,1-Trichloroethane & $40-60$ & $20-40$ & $30-220$ \\
Carbon Tetrachloride & $35-40$ & $20-40$ & $40-70$ \\
cis-1,2-Dichloroethene & $55-75$ & $20-40$ & $35-250$ \\
1,2-Dichloroethane & $40-55$ & $20-40$ & $45-130$
\end{tabular}


replacement of the packing media can be ignored since this cost is a function of solids concentration), a direct comparison of ASH technology with packed tower can be obtained. Results are given in Table 4. In this table, the cost on ASH is estimated by APT's engineer while the cost for the packed tower is provided by Radian Corporation. As can be seen from the table, in such an ideal case, the ASH technology has a slightly higher power cost, but a significantly lower capital investment cost and yearly O\&M cost.

Further, as described in Phase I proposal, in addition to savings in capital equipment and operation costs, other advantages of ASH technology include:

a) ASH can operate VOC stripping directly from a slurry containing solids at a concentration up to $20 \%$ or higher due to its unique design features. This is a key advantage that no any other technologies can complement.

b) Due to its high processing capacity ( 100 - 600 times more than other technologies for gallons processed per unit time per unit equipment volume), ASH system is compact and mobile. Entire system can be constructed on a small mobile trailer and transported to different locations/sites for different applications. This is an advantage that permanently installed, giant packed tower can never achieve.

As a visual illustration, Figure 3 provides photos of the air-sparged hydrocyclone technology/equipment. The top photo shows APT's trailer-mounted, self-contained mobile system (processing capacity 20 gallons per minute), the left photo is a 2 -inch inner diameter (actually $1.875 "$ ID) by 20 -inch length ASH-2C air-sparged hydrocyclone specially designed for VOC stripping. Photos was taken during TCE stripping work for Radian.

It needs to be pointed out here that ASH system used for VOC stripping has two major differences as compared to the system used in particle separation (such as radionuclide, heavy metals, oil, etc.). First, it needs to accommodate a much higher dimensionless flowrate ratio (air flowrate to water flowrate at about 40 to 1). Second, ASH underflow structure used in VOC 
Table 4. Comparison of ASH with Packed Tower Stripping Based on TCE Removal from Water at $95 \%$ Removal Efficiency

\begin{tabular}{|c|c|c|c|c|c|c|}
\hline \multicolumn{3}{|c|}{ Capacity Capital Investment $(K \$)$} & \multicolumn{2}{|c|}{ Yearly Power Cost $(\mathrm{K} \$)$} & \multicolumn{2}{|c|}{ Yearly O\&M Cost $(K \$)$} \\
\hline & Stripper & $\underline{A S H}$ & Stripper & $\underline{\mathrm{ASH}}$ & Stripper & $\underline{A S H}$ \\
\hline 20 GPM & 56 & 13 & 0.29 & 0.69 & 29 & 2.7 \\
\hline 100 GPM & 77 & 21 & 0.9 & 3.4 & 31 & 13.5 \\
\hline 700 GPM & 160 & 42 & 5.7 & 24 & 45 & 31.2 \\
\hline
\end{tabular}




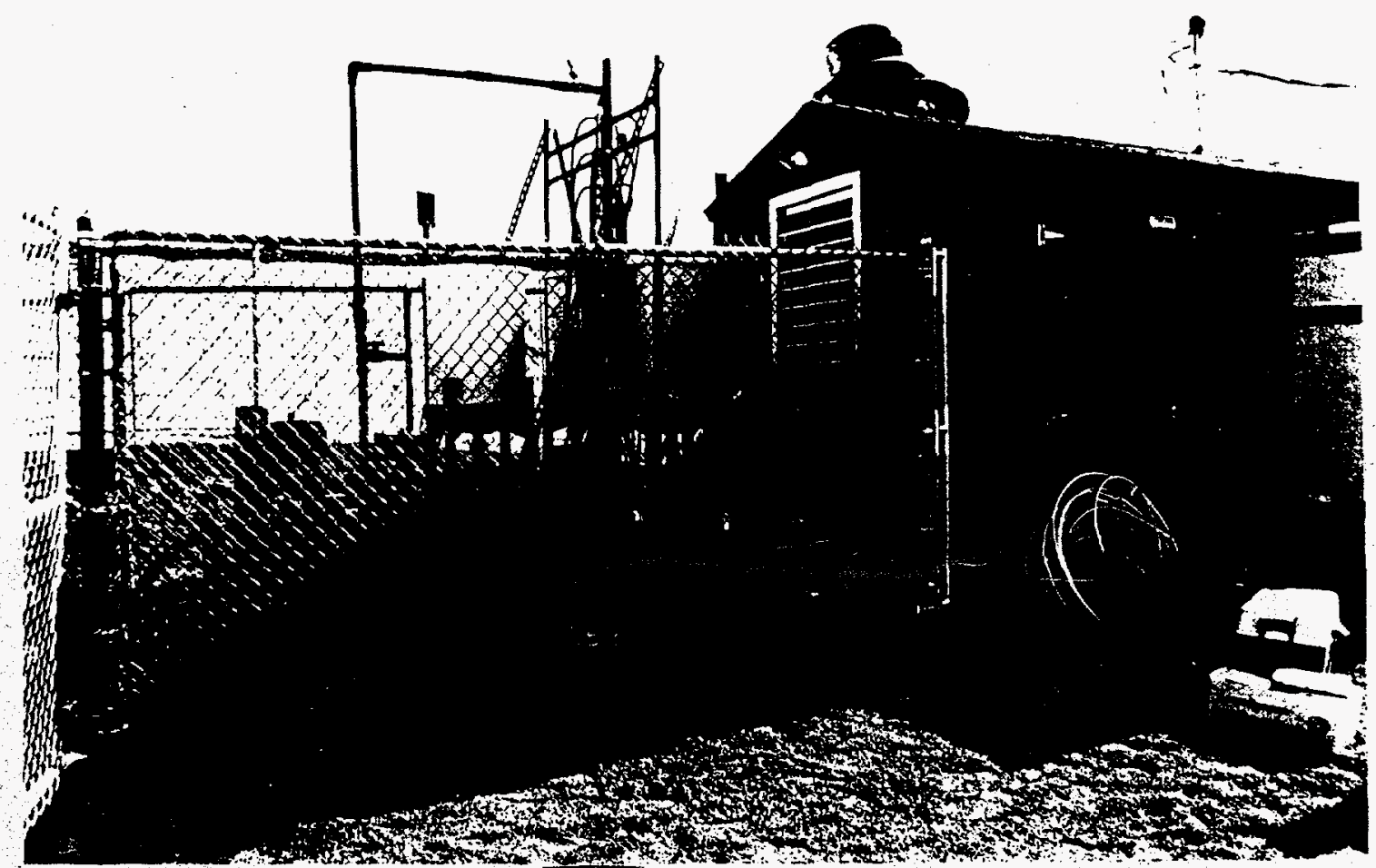

Figure 3. Photos of the air-sparged hydrocyclone technology/equipment

Top: APT's trailer-mounted, selfcontained mobile system (processing capacity 20 gallons per minute)

Left: a 2 inch inner diameter by 20 inch length $\mathrm{ASH}-2 \mathrm{C}$ arr-sparged hydrocyclone.

Photos was taken during a test which APT conducted recently for Radian Corporation to remove TCE from underground water. The ASH-2C shown in the photo has different design for the purpose of VOC removal. 
stripping is totally different from particle separation to accommodate the separation of water from air immediately after VOC stripped.

C) Oil removal -- This application refers to two different situations: 1) oil removal from water, and 2) oil removal from contaminated soil. For 1), it mainly refers to the removal of physically dispersed oil particles from an oil/water emulsion. For 2 ), the oil contaminated soil has to be slurried first, followed by ASH flotation with sir.ilar principles in both particle flotation and oil flotation applied to ASH technology to separate oil droplets from others.

Oil contamination is also a problem in many DOE sites as documented by "US DOE Interim Mixed Waste Inventory Report: Waste Streams, Treatment Capacities, and Technologies, April, 1993". This contamination often happens together with other contaminants. For example, for Test Area North Well located at Idaho National Engineering Lab, the water has been contaminated by DNAPL, VOC, oil, and radionuclide all together. It poses a significant problem and complexity in actual clean-up work. This is the reason why removal of oil from water or soil was later added/expanded as another technical consideration for the technology.

APT during past several years (and up to present time) has carried out appreciable amount of R\&D work in this area. Application of the technology in this field is considered by APT as having multi-advantages and competitiveness as compared with conventional DAF, tiquid/liquid cyclones, and/or other flotation machines for different waters containing emulsion- stabilizing agent and/or produced waters in oil industry. While detailed explanations are omitted here, a visual illustration is provided in Figure 4 which is a photo of samples of cleaned water and concentrated oil collected from an ASH-2C testing which APT conducted recently for another project. Feed stream, at a flowrate of $21 \mathrm{gpm}$, contains about 1,240 ppm oil, the cleaned water 


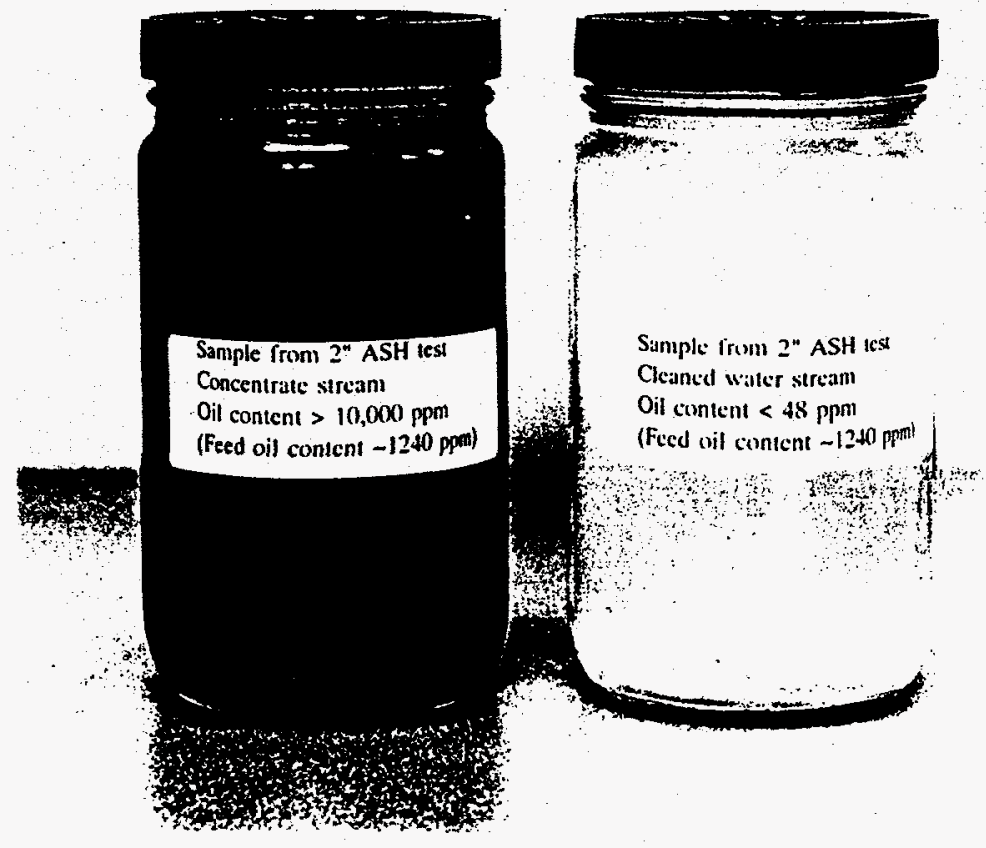

Figure 4. Photo of samples collected from a 2" diameter ASH-2C unit test for oil removal from water.

Feed stream:

washrack wastewater, oil content $1,240 \mathrm{ppm}$

Test condition:

Left bottle:

Right bottle:

single stage at a flowrate of $21 \mathrm{gpm}$

collected concentrate stream with oil $>10,000 \mathrm{ppm}$

Performance: collected cleaned water stream with oil $<48 \mathrm{ppm}$ oil removal $96 \%$, water recovery $90 \%$ 
(shown on right) contains only a residual oil concentration at about $48 \mathrm{ppm}$, the concentrate stream contains $>10,000 \mathrm{ppm}$ oil (shown on left), the oil removal efficiency obtained is $96 \%$, while the water recovery is $90 \%$. This performance was obtained only based on a single unit, one stage processing. If the system is a circuit equipped with three ASH units, an oil removal efficiency greater than $99 \%$ and a water recovery higher than $99 \%$ can be obtained. Detailed description of principles involved in ASH technology (and other technologies) for oil removal from water is omitted here.

D) DNAPL removal from water -- At present time, ASH technology for DNAPL removal from water is only a concept and theoretical consideration based on phy wal and chemical properties of DNAPLs and principles of ASH technology. After DNAPL is proposed to be considered in current work scope per project kick-off meeting, APT's engineers have studied perspectives of this application. Analysis obtained indicates that ASH technology would be applicable with a fairly high possibility of success. This conclusion is based on following two considerations:

a) many DNAPLs are hydrophobic, they can be separated in a way similar to oil droplet flotation separation by ASH if they can be broken into fine droplets prior to and during the flotation;

b) at a concentration level below the phase separation, DNAPLs can be stripped out by air stripping technologies, the same as the stripping for other VOCs.

In this way, proposed concept for ASH in this field of application, based on current study, is schematically shown in Figure 5. In summary, an in-line mixer is added into the feed pipe before DNAPL/water enters into the ASH unit. DNAPL contained in feed water thus can be broken into fine droplets by in-line mixer and flow motion during pumping. Mixer type and 


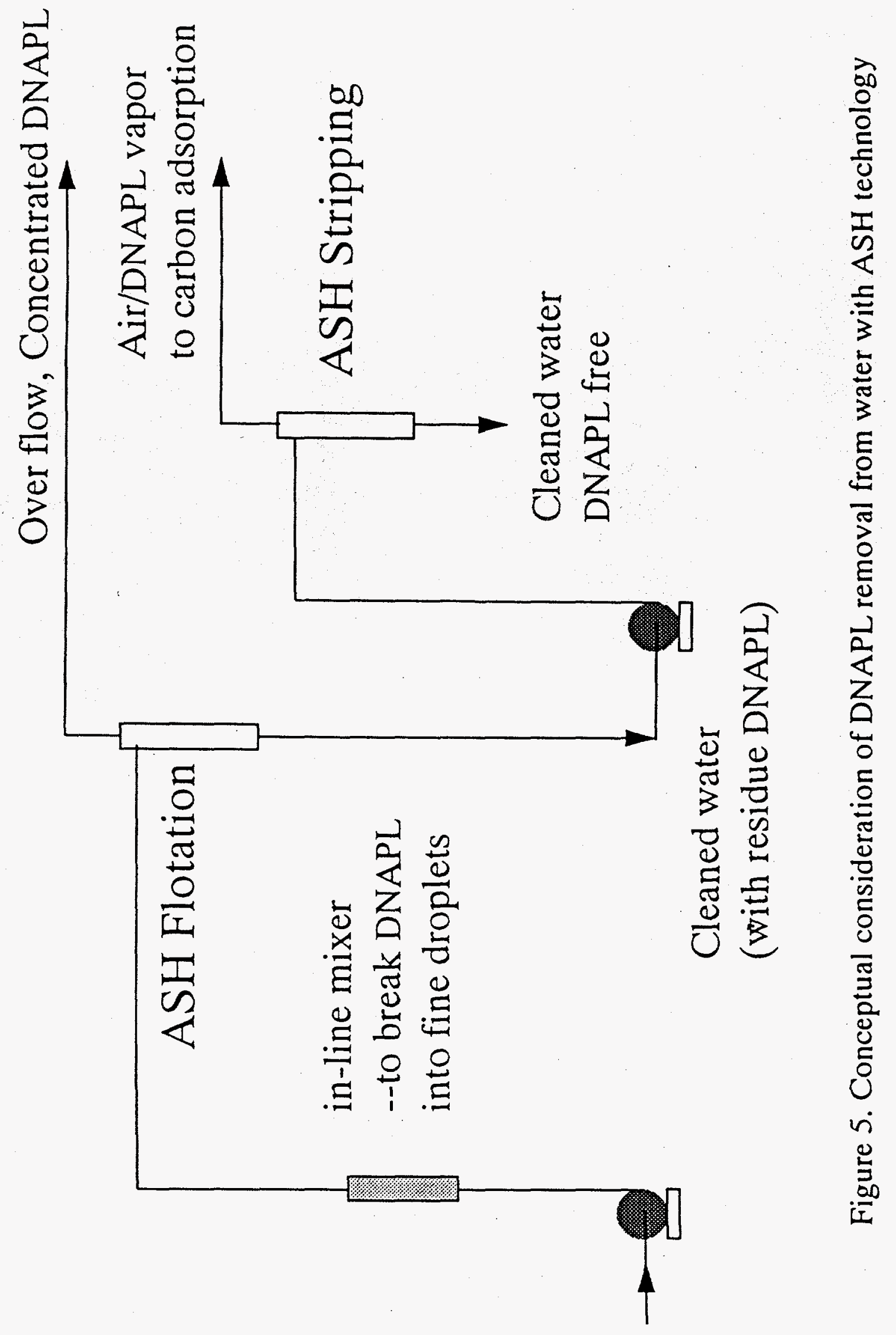


additional required pumping energy are parameters which need to be investigated and optimized so that the size of DNAPL droplets thus formed can fit the flotation separation requirements by ASH technology. Also, distance from the in-line mixer to the inlet of ASH unit is another parameter which needs to be considered to prevent coalescence of these fine droplets after their formation (The coalescence of these droplets insider ASH could have a minimum effect since retention time of water inside the ASH system is extremely short. For example, for a 2-inch diameter ASH-2C unit, the retention time is only at 0.1-0.3 second). After the flotation separation, the residue DNAPL contained in discharged water thus then is stripped out by another ASH unit.

\section{Proposed Differential Separation Concept}

The original differential separation concept, as briefly discussed at the beginning, was based on the consideration that to decontaminate a site containing multi-contaminants, a combination of different types of technologies/equipment is needed. This practice significantly raises the cost of the decontamination process and causes a complexity and difficulty of the process as compared with single technology for a single application which is already a difficult task. If technically possible, a key technology/equipment should be developed to prosess/remove different contaminants step-by-step through proper engineering and circuit design. The successful development of such a technology/circuit will significantly reduce the complexity, capital equipment cost, and operation cost of the decontamination process. The key requirement is that the technology to be considered shall have diversified functions to handle different contaminants. ASH technology was recommended by APT as to be capable of playing such a role in process. 
Figure 6 is a flowsheet schematically showing the concept for differential separation of both radionuclide particles and VOC from a slurry with ASH technology. The slurry is first placed into a container (or lagoon) to allow sedimentation of most solid particles. After this step, the slurry is split into two portions. One has a high solid concentration (or sludge/cake), another has a relatively low solid concentration. The portion which has a low solid concentration is processed first to remove VOC from water by stripping. VOC free water then is mixed together with the portion having high solid concentration to allow phase transfer of residue VOC contained in soil into water, then VOC stripping for the slurry is conducted again. After this step, ASH separation fi adionuclide particles thus can be conducted and finai discharged streams are a) a slurry containing VOC and radionuclide at an allowable discharge limit and b) a highly concentrated stream containing most of radionuclide particles. In this practice, significant reduction in capital equipment and operation costs can be achieved. This concept, together with removal of other contaminants, is yet to be demonstrated.

\section{Summery}

The air-sparged hydrocyclone technology is one of the technologies in environmental fields has been under the development by APT during the past several years and the technology has been successfully demonstrated to have a diversified functions to remove different contaminants from different streams. This may provide a unique opportunity and offer a strong potential for the removal of radionuclides, VOC, oil, DNAPL and others from contaminated soil and groundwater through a differential removal process. 

